\title{
Valuing animal genetic resources: a choice modeling application to indigenous cattle in Kenya
}

\author{
Eric Ruto ${ }^{\mathrm{a}^{*}}$, Guy Garrod ${ }^{\mathrm{a}}$ and Riccardo Scarpa ${ }^{\mathrm{b}}$

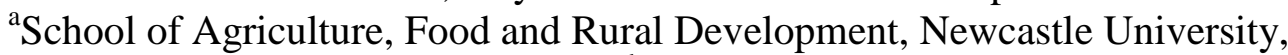 \\ Newcastle upon Tyne, NE1 7RU, UK; ${ }^{b}$ Department of Economics, University of \\ Waikato, Private Bag 3105, Hamilton, New Zealand
}

\begin{abstract}
In an effort to improve productivity and profits many farmers have replaced traditional livestock breeds with higher yielding alternatives. While such changes may bring about short-term economic gains, the loss of traditional livestock breeds could result in the loss of an important genetic resource as a variety of important genetic traits adapted to local conditions gradually become less common in the population. This is a particular problem in Africa, where livestock make a substantial contribution to human livelihoods. Using the example of cattle in Kenya's pastoral livestock markets this study uses a choice experiment approach to investigate buyers' preferences for indigenous breeds such as the Maasai Zebu. The analysis employs a latent class approach to characterize heterogeneity in valuations both within and across respondents buying cattle for breeding, slaughter or resale. The results show that there are at least three classes of buyers with distinct preferences for cattle traits and that most buyers favor exotic rather than indigenous breeds. Such preferences have implications for the conservation of indigenous cattle in Kenya and in other developing countries and suggest that some form of intervention may be required to ensure the preservation of this important animal genetic resource.
\end{abstract}

JEL Classification: Q12, Q16, Q18, Q57

Key words: animal genetic resources; conservation; economic valuation; choice experiments; latent class models; indigenous livestock; Kenya

${ }^{*}$ Corresponding author. Tel.: +44-191-2223593; Fax: +44-191-2225411

E-mail address: Eric.Ruto@newcastle.ac.uk (Eric Ruto) 


\section{Introduction}

There is increasing global concern about the potential long term consequences of loss of domestic animal diversity. The ratification of the Convention on Biological Diversity (CBD, 1992) represents international consensus to conserve biodiversity including that of farm animal genetic resources (AnGR) and plant genetic resources, which are prerequisites for food security and the future of agricultural innovations. Much of the world's surviving AnGR diversity reside in developing countries i.e. in those countries least able to finance its conservation and least able to resist the forces that drive biodiversity decline (CBD, 1992).

In Africa, low input subsistence farming and pastoral production systems dominate. In these systems livestock make a particularly important contribution to human livelihoods. They serve as household assets with multiple livelihood functions, providing not only food and income but also important non-market services such as draught power and manure for crop production (Anderson, 2003). Contributions and/or exchanges of cattle also characterize important cultural and social transactions such as marriage, reciprocity and death payments. In the last century however many livestock development projects have sought to improve the productivity of local livestock, in terms of increasing the output of marketable products such as meat and milk, by promoting the extensive use of exotic germplasm in cross-breeding (Rege, 1999).

The introduction of exotic breeds and other social and economic pressures have exposed locally adapted indigenous breeds to the risk of extinction and could lead to a loss of potentially valuable genetic diversity (Rege and Gibson, 2003). For example, Rege (1999), drawing on a survey of cattle genetic resources in sub-Saharan Africa, revealed that 32 percent of the 145 cattle breeds identified were considered to be at risk of extinction. There are several factors that underlie these trends, some of which are driven by the lack of comparative economic competitiveness in indigenous breeds. Ayalew et al. (2003) argue that conventional productivity evaluation criteria are inadequate to evaluate subsistence livestock production and have tended to overestimate the benefits of cross-breeding and breed substitution. Drucker et al. (2001) and Roosen et al. (2005) argue that markets generally fail to completely capture the value of locally adapted AnGR as potential stocks of genes that can serve as a source for future breeding, or as source of non-market benefits. As these authors point out, a consequence of such market "failure" is that economic incentives are distorted in favor of the economic activities (such as cross-breeding) that erode potentially valuable AnGR rather than conserving them.

The indigenous Zebu cattle breeds in Kenya are an example of AnGR currently at risk of extinction (Rege, et al., 2001). These cattle are perceived as a repository of the diversity of cattle genotypes of all East Africa (Hanotte et al., 2002). The Zebu cattle are thought to have superior adaptive attributes to local environmental stresses (such as resistance to disease and drought) compared to exotic breeds. The diversity of this 'genetic resource' is a key component of the ability of a pastoral agricultural system to overcome destabilizing factors given uncertainty over production environments in the future such as climate change, disease and changing market demands. There is therefore a clear justification for their conservation. However, Kenya lacks a comprehensive policy for the conservation and breeding of indigenous cattle (Mwacharo and Mossi, 2002). 
The management of AnGR requires many decisions that would be made easier if information on the economic value of populations (e.g. breeds) and their adapted characteristics were available. However, economic valuation of AnGR within subsistence production systems typical of developing countries is only in the early stages of development. Recent reviews of potential AnGR valuation methods by Drucker et al. (2001) and Roosen et. al. (2005), have highlighted the potential role of non-market valuation methodologies in valuing AnGR in developing countries. This follows from the premise that many of the benefits derived from the existence of well adapted indigenous breeds are not transacted in any market. Recent applications show that such methodologies reveal useful estimates of the values that are placed on the market, non-market and potential breed attributes (Jabbar and Diedhiou, 2003; Scarpa et al., 2003a; Scarpa et al., 2003b; Tano et al., 2003) (see also Birol et al., 2006 for an application in plant genetic resource valuation).

This paper contributes to the growing literature on AnGR valuation, using indigenous cattle in Kenya as a case study. We use a stated preference approach namely choice experiments (Louviere et al., 2001) to investigate buyers' preferences over cattle traits in Kenyan livestock markets. The main objective is to assess how buyers value a typical indigenous cattle breed (Maasai Zebu) and to characterize heterogeneity in valuations both within and across respondents buying cattle for various purposes. Such preferences have implications for the conservation of indigenous cattle in Kenya and in other developing countries. The remainder of this paper is organized as follows. Section 2 provides an overview of recent developments in the literature on the treatment of heterogeneous preferences in random utility models and then discusses the choice modeling approach adopted in this paper. In section 3, we describe the study sites and the methods used to collect data. Section 4 reports the findings from the analysis of choice experiment data. Conclusions are drawn in the final section.

\section{Theory and methods}

\subsection{Accounting for heterogeneous preferences}

In Kenyan livestock markets, agents buy livestock for diverse purposes hence preferences for cattle breeds or traits may be expected to vary considerably across individuals. It is important to understand the extent and form of the heterogeneity in breed preferences across the population of market agents as this would potentially promote the policy usefulness of the results. Traditional methods of analyzing choices using the multinomial logit (MNL) model (McFadden, 1974) are clearly limiting as they assume homogeneity of preferences. Commonly used approaches to representing heterogeneity in choice models are through either a continuous or discrete distribution of utility parameters - the former via mixed logit models (Train, 2003; McFadden and Train, 2000) and the latter using latent class models (Wedel and Kamakura, 2000). 
In this paper, we employ the latent class $\operatorname{model}^{1}$. Here, the premise is that the population consists of a finite (and identifiable) number of groups of individuals (segments), each characterized by relatively homogenous preferences. However, these segments differ substantially in their preference structures. A key feature of this approach is that it accommodates preference heterogeneity while allowing the number of segments to be determined (endogenously) by the data. In this context, belonging to a segment with specific preferences is probabilistic, perhaps based on buyer characteristics such as the individual motives for buying cattle. The latent class model is a classic implementation of this approach. These models were originally used in market research (Kamakura and Russel, 1989; Gupta and Chintagunta, 1994; Swait, 1994). According to these studies, latent class models can provide results that are quite 'actionable' in terms of effective product targeting and strategic positioning.

More recently, latent class models have been used in travel cost revealed preference studies (e.g. Morey et al., 2006; Provencher et al., 2002; Scarpa and Thiene, 2005) and stated preference applications (for an application in food choice see $\mathrm{Hu}$ et al., 2004). The latter include a study by Greene and Hensher (2003) in which the merits of mixed logit are systematically contrasted with those of latent class modeling in terms of choice elasticities, distributions of predicted choice probabilities and changes in absolute choice shares. They conclude that no unambiguous recommendation can be made as to the superiority of either of the two approaches, though they find stronger statistical support overall for the latent class approach with three preference segments.

Boxall and Adamowicz (2002), in an application investigating the choice of outdoor recreation, used factor analysis to provide estimates of motivational determinants of recreational trips to wilderness that were then used in the specification of the segment membership likelihood function. Their analysis supported the existence of four segments of recreationists and permitted a much richer interpretation of the data than the standard (single segment) MNL model. This is supported by Scarpa et al. (2003b) who used latent class analysis to corroborate the results of conditional heterogeneity MNL analysis of household preferences for pig breeds in the Yucatan province of Mexico. They found evidence of two segments with distinct preferences, using various socio-economic characteristics (e.g. age, household size and income) as determinants of the respondents' probability of segment membership. They posit that the results from their latent class analysis were much more informative than those obtained from their MNL model with interaction variables.

These studies generally acknowledge the policy usefulness of accounting for preference heterogeneity at the segment level and have highlighted this approach as an area of potentially novel research that requires further empirical applications in stated preference studies. This paper provides a contribution to the growing literature in this area and represents one of the few empirical applications of the latent class approach to an agricultural problem in a developing country.

\footnotetext{
${ }^{1}$ There is no theoretical reason to use one or the other approaches (mixed logit or latent class models (LCMs)). We estimated the mixed logit model as well (results are available from the authors on request) and the results are similar to the results of the LCM. We chose to present the results of the LCM in this paper. It may be noted however that LCMs are a special category of mixed logit models in which the mixing distribution is finite. So strictly speaking, we are using a mixed logit model.
} 


\subsection{The latent class model of cattle choice}

Formally, consider that individual $n$ faces a choice of selecting the preferred alternative amongst a set of $J$ alternatives of cattle in each of the $T(n)$ choice occasions. Suppose individual $n$ belongs to segment $s \in S$, then his utility function associated with the preferred alternative $i \in J$ can be written as:

$$
U(\text { int } \mid s)=\beta_{s}^{\prime} X_{\text {int }}+\varepsilon_{\text {int } \mid s}
$$

Assuming a random utility framework as the basis of an individual's choice and an independent-identically-distributed (IID) extreme value type I stochastic component of an individual's utility for the preferred choice, the joint logit probability of a set of choices $T(n)$ made by individual $n$, conditional on belonging to a given segment $s$ is:

$$
P_{T(n)} \mid s=\prod_{t(n)}^{T(n)} \frac{\exp \left(\beta_{s}^{\prime} X_{\mathrm{int}}\right)}{\sum_{j=1}^{J} \exp \left(\beta_{s}^{\prime} X_{j n t}\right)}
$$

where in equations 1 and 2, $X_{\text {int }}$ is a vector of observable attributes associated with alternative $i$ and individual $n$ observed making a choice on occasion $t$, and $\beta_{\mathrm{s}}$ is a conformable (segment-specific) vector of taste parameters. Note that the scale parameter is normalized to one. The differences in the $\beta_{\mathrm{s}}$ vectors enable this approach to capture heterogeneity in preferences for the cattle-choice attributes across segments.

Now consider an individual's segment membership likelihood function $M^{*}$ that classifies cattle buyers into one of the $S$ latent segments. The classification variables influencing segment membership are perhaps related to observed individual motivations for buying cattle. This is represented by a vector of 'purpose of buying' variables (labeled $Z$ ), used here as proxies for individual motivational factors influencing cattle choices. The membership likelihood function for buyer $n$ and segment $s$ can be expressed as: $M_{n s}^{*}=\lambda_{s} Z_{n}+\xi_{n s}$. Assuming the error terms in the individual membership likelihood functions are IID extreme value type I across individuals and segments, the probability that buyer $n$ belongs to segment $s$ can be expressed in an MNL form as:

$$
P(s)=\frac{\exp \left(\lambda_{s} Z_{n}\right)}{\sum_{s=1}^{S} \exp \left(\lambda_{s} Z_{n}\right)}
$$

Where $\lambda_{s}(s=1,2, \ldots, S)$ are segment-specific parameters to be estimated, that denote the contribution of the various buyer motivational factors to the probability of segment membership: a positive $\lambda$ implies that the associated buyer descriptor variable $Z_{n}$ increases the prior probability that buyer $n$ belongs to segment $s$. The scale 
factor is normalized to unity. $P(s)$ sums to one across the $S$ (to be determined) latent segments with $0 \leq P(s) \leq 1$.

Recall that equation 2 provides the conditional (on membership of a particular segment $s$ ) choice probability. The unconditional joint probability of a set of choices $T(n)$ for individual $n$ is obtained by combining the conditional probability with the segment membership probability by means of taking the expectation over all the $S$ segments:

$$
\operatorname{Pr}(T(n))=\sum_{s=1}^{S}\left[\left(\frac{\exp \left(\lambda_{s} Z_{n}\right)}{\sum_{s=1}^{S} \exp \left(\lambda_{s} Z_{n}\right)}\right)\left(\prod_{t(n)}^{T(n)} \frac{\exp \left(\beta_{s} X_{\mathrm{int}}\right)}{\sum_{j=1}^{J} \exp \left(\beta_{s} X_{j n t}\right)}\right]\right.
$$

The sample log-likelihood function that is maximized to obtain the parameters $\lambda_{s}$ and $\beta_{s}$ is given by (where $I_{i}$ is an indicator variable for the observed choice):

$$
L=\sum_{n} \sum_{i \in J} I_{i} \ln \operatorname{Pr}(T(n))
$$

Once the parameter estimates have been obtained, a measure of economic value can be derived for each animal attribute using the formula given in equation 6 below (Hanemann, 1984). These ratios (often referred to as marginal implicit prices) can also be interpreted as a marginal rate of substitution (MRS) between animal attributes and money: the coefficient $\beta_{m}$ gives the marginal utility of income and is the coefficient of the price attribute and $\beta_{k}$ is the coefficient on the cattle attributes:

$$
M R S_{k s}=-\frac{\beta_{s k}}{\beta_{s m}}
$$

The determination of the number of segments $(S)$ appropriate to characterize a given population is not part of the maximization procedure from which the parameter estimates are derived. The standard procedure is to sequentially estimate model parameters for increasing values of segments $S(S=2,3,4, \ldots)$ until a point is reached where an additional segment does not improve model fit as measured by some criterion. However, statistical tests for evaluating the differences in model fit between successive segment models are still not available. In particular, neither the likelihood ratio test statistic, nor its Wald test and Langrange Multiplier test counterparts, meets the regularity conditions necessary for a limiting chi-square distribution (McLachlan and Peel, 2000; Wedel and Kamakura, 2000). As a guide, information theoretic criteria such as the Akaike Information Criteria (AIC) and the Bayesian Information Criteria (BIC) are frequently used to determine the number of segments. However, the researcher's judgment, interpretability of the model and the overall "parsimony" of the model along with its matching with prior information 
(theoretical and otherwise) are key factors which also come into play in selecting the appropriate number of segments. The aim is to avoid choosing superfluous segments that do not add to our understanding of the underlying behavioral process (Swait, 1994).

\section{Choice experiment survey}

This paper uses data collected through a choice experiment (CE) survey of livestock markets in the district of Kajiado, Southern Kenya (see figure 1). The area (21,903 $\mathrm{km}^{2}$ ) runs from just south and west of the capital city (Nairobi) to the border with Tanzanian. Most of the district lies in the arid and semi-arid zones (mean annual rainfall ranging from 300 to $800 \mathrm{~mm}$ ), and only $8 \%$ of its land has some potential for cropping (Bekure et al., 1991). Savannah grasslands dominate the area. Livestock and wildlife co-exist in much of this area, with several major National Parks (Nairobi, Amboselli, Tsavo) bordering or falling within the district. The area is inhabited mainly by Maasai pastoralists whose livelihood depends heavily on livestock.

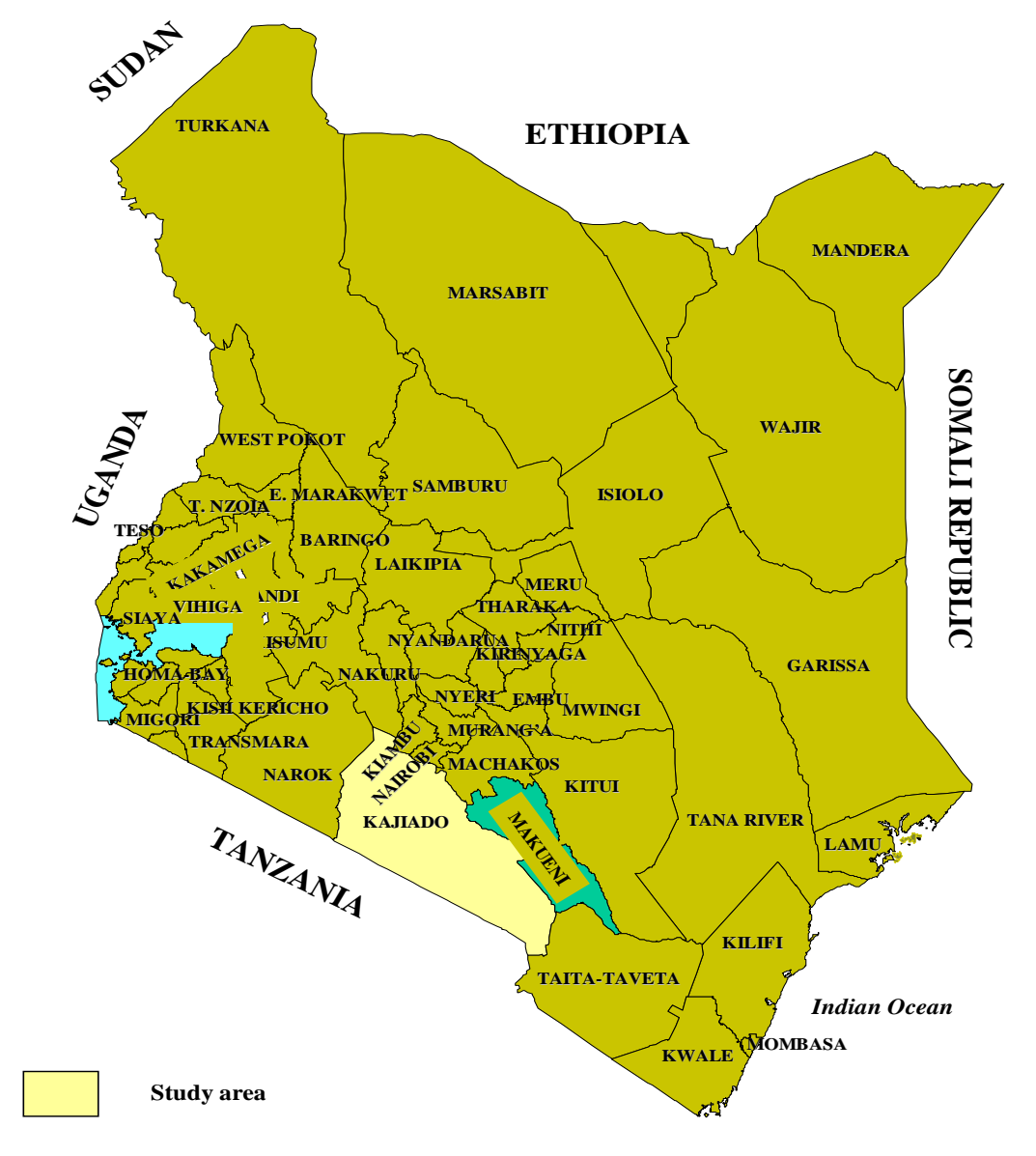

Figure 1. Geographical region where the study was done. 
The CE survey was carried out in seven (out of thirteen) livestock markets. These were Emali, Kiserian, Rombo, Kimana, Bissel, Sajiloni and Oldonyonyokie livestock markets. The seven markets were selected because they represent the key livestock markets used by pastoralists in southern Kenya. Their spatial distribution reflects the local structure of cattle marketing and, in particular, the movement of livestock from primary to secondary markets. They were, therefore, expected to represent reasonably well the reality of cattle trade in inland Kenya, especially in terms of the diversity of market participants and livestock breeds traded.

Emali is one of the largest cattle markets in Kajiado district and one of the biggest livestock markets in Kenya. The volume of cattle traded on a typical market day range from 800 to $2000^{2}$ head of cattle. Kiserian market borders Nairobi and supplies beef to this major consumption centre. It has slaughter facilities for livestock and receives animals from different parts of the country including northern Kenya. It operates six days a week with approximately 600 to 800 animals traded each market day. Bissel is also a busy livestock market with good slaughter facilities supplying beef directly to Nairobi. Rombo and Kimana markets are quite similar in their characteristics. They are located on the slopes of Mount Kilimanjaro at the border of Kenya and Tanzania, are extremely remote and less accessible. The volume of animals traded is relatively small, ranging from 400 to 800 head of cattle per market day in each market. Pastoralists frequently use these markets to purchase animals for their own herds (i.e. for rearing or breeding). Sajiloni is a market in the outskirts of Kajiado town. It handles an average of 600 animal transactions each market day. Oldonyonyokie is one of the major feeder markets of cattle to Kiserian market. It is served by a relatively good road (Nairobi-Magadi road). It is also an important 'next-stop' market for animals traded at the Tanzania border market of Torosei. Maren et al. (2006) report that about 50 percent of cattle traded in Kajiado markets are indigenous (Maasai zebu) breeds, the rest being zebu cross breeds and non-native (exotic) breeds such as Sahiwal and Boran.

All markets in the study area have no formal infrastructure, and transactions occur (usually under tree shades) through bilateral negotiations between buyer and seller, as opposed to a competitive auction. Three types of buyers can be identified. The first (we refer to as slaughter buyers) are those who buy livestock for butchers in Nairobi or other areas in or outside the district. The second type (we refer to as resalers or resale buyers) are involved in speculative purchases; they buy animals that they then sell in the same or other markets a few days later or even the same day. They usually make a living off small margins from a large number of transactions. Finally, the third group (we refer to as breeders) purchase animals for breeding or to re-stock their own herds. As earlier alluded to, one key objective of the empirical analysis in this paper is to investigate the extent to which the relative valuations of cattle attributes and breeds are influenced by the purpose of the individual purchase.

The CE survey was targeted at cattle producers and traders observed in the process of negotiating for and purchasing cattle. For each of the seven markets, local enumerators with secondary or post secondary education were recruited and trained. They were all familiar with the operation of the livestock markets and spoke at least one local language in the study area. During enumerator training, particular emphasis

\footnotetext{
${ }^{2}$ Figures on the volume of livestock traded in the sampled markets are drawn from Ruto (2004).
} 
was dedicated to random sampling techniques. In this type of survey, however, it was not possible to obtain a true random sample as no complete list of potential respondents existed. Respondents were interviewed face-to-face on a "next to pass" basis as opposed to opportunistic sampling. Data were collected on 12 market days (usually Friday) from September through November 2000. Interviews were carried out between 12 noon and $3.00 \mathrm{pm}$ - that is the time of the day when most market transactions have been carried out and the respondents are more relaxed and ready to talk.

In the CE design, the following cattle attributes were selected: breed of animal, sex, body condition, weight and price. The selection of attributes and levels relied on informal interviews of livestock traders and on information from an exploratory market survey previously conducted, in the same study area and markets, by researchers in Kenya Agricultural Research Institute (Ruto, 1999). Table 1 reports descriptive statistics of the characteristics of cattle traded, prices and the motivations of market participants from this 1999 market survey. The results of the exploratory survey showed that weight, sex and body condition of the animal explained about 70 per cent of observed transaction prices. Unfortunately, no breed records were collected from these transactions, and no background information on the effect of breed on market price was available. Thus the same attributes were incorporated in the $\mathrm{CE}$, with an additional inclusion of breed as one of the attributes.

Table 1: Characteristics of animals traded and purpose of purchase

\begin{tabular}{lccc}
\hline & $\begin{array}{c}\text { Number } \\
(\% \text { of total) }\end{array}$ & $\begin{array}{c}\text { Mean estimated } \\
\text { weight in Kg } \\
\text { (standard deviation) }\end{array}$ & $\begin{array}{c}\text { Mean price in Ksh } \\
\text { (standard deviation) }\end{array}$ \\
\hline $\begin{array}{l}\text { All } \\
\text { Mex of animal }\end{array}$ & $448(100 \%)$ & $133(51)$ & $11,124(5772)$ \\
Male & $262(59 \%)$ & $147(52)$ & $13,224(6149)$ \\
Bemale & $186(41 \%)$ & $109(38)$ & $8,165(3480)$ \\
animal & & & \\
Excellent & $26(6 \%)$ & $202(42)$ & $19,173(76860$ \\
Good & $222(49 \%)$ & $140(49)$ & $12,829(5182)$ \\
Fair & $161(36 \%)$ & $118(41)$ & $8,982(4055)$ \\
Poor & $39(9 \%)$ & $74(32)$ & $4,892(2649)$ \\
Purpose of & & & \\
purchase & Slaughter & $141(56)$ & $13,133(6267)$ \\
Resale & $212(47 \%)$ & $122(41)$ & $11,065(4479)$ \\
Breeding & $151(34 \%)$ & $120(50)$ & $6,216(2876)$ \\
\hline Source: Kation & $85(19 \%)$ & &
\end{tabular}

Source: Kajiado district market survey (Ruto, 1999)

As Batsell and Louviere (1991) point out, an important objective in CE design is that of easing the choice task for respondents. This is particularly crucial in our case because of the distracting, busy and competitive environment in which cattle dealers operate. Hence in deciding on the number of levels that each attribute was to take, a degree of pragmatism was involved. The breed attribute had two levels: indigenous 
breed (i.e. Maasai Zebu) and exotic (Non-Zebu) breeds. The body condition attribute was also varied at two levels; good/excellent or poor. Finally, the weight and price attributes were each allotted three levels based on the range of prices and weights of animals across sex and body condition classes observed in the exploratory survey. Information from informal interviews with livestock traders also helped to ensure that the prices incorporated in the choice experiment were commensurate with the range of prices for different breeds of cattle.

Given the set of attributes and the levels that each attribute would take, experimental design methods (see Louviere et al., 2000) were used to structure paired comparisons of 'animal profiles' or choice sets. A large number of unique animal profiles can be constructed from this number of attributes and levels. We used the orthogonal fractional factorial experimental design facility in SPSS for Windows (SPSS, 2000) to recover only the main effects consisting of 16 animal profiles. These were randomized into eight choice sets or pair-wise comparisons of animal profiles to be presented to respondents. Each set contained two animal profiles and an option to select neither. As mentioned earlier, one paramount objective in the survey design was that of easing the choice tasks for respondents. A pilot exercise for the CE showed that respondents could comfortably manage anything up to up to eight choice tasks.

Thus a typical choice task required respondents to decide which of two hypothetical cattle purchase choices (say A and B) they preferred. Each choice was described to the respondents in terms of the five attributes discussed previously: sex, breed, weight, body condition and price. They were then asked to decide whether they preferred A, B or neither. For example Buyer 1 was asked the following question: "Would you buy animal A: a male non-Zebu breed that weighs $120 \mathrm{~kg}$, is in poor condition and costs Kenya Shillings $(\mathrm{Ksh})^{3}$ 12,000, or animal B, a female Maasai Zebu that weighs $90 \mathrm{~kg}$, is in excellent condition and costs Ksh 10,000, or neither?" In addition, respondents were asked why they were buying animals that market day (e.g. for slaughter, resale or breeding).

Each animal profile presented to a respondent was represented on a separate laminated card (explained in the local language) and photographs of cattle were used to demonstrate the variable 'body condition' to respondents. The enumerators interviewed 311 respondents for a total of 2488 choice tasks, usually undertaking four interviews per market day. All respondents approached agreed to participate in the survey and each completed all the eight choice tasks.

\section{Results and Discussion}

Table 2 provides a description of the variables employed in the estimation of the latent class models. The discussion of empirical results is organized as follows. First, the results of the procedure to determine the number of segments are reported. Next, estimates of the 'optimal' model which consists of a set of probabilities defined over segments and segment specific parameters are discussed ${ }^{4}$.

\footnotetext{
${ }^{3}$ Seventy six Kenya Shillings was equivalent to one US Dollar at the time of the survey.

4 All the model estimations were carried using the Expectation-Maximization (EM) algorithm (implemented in Latent Gold Choice $₫$ econometric software).
} 
Table 2: Description of variables used in the choice experiment

\begin{tabular}{|c|c|}
\hline Variable & Description \\
\hline \multicolumn{2}{|l|}{ Animal attributes } \\
\hline Price & Price of animal (Ksh) \\
\hline Cow & $\begin{array}{l}\text { Sex of animal: } \\
\text { Cow }=1 \text { if female } 0 \text { otherwise }\end{array}$ \\
\hline Zebu & $\begin{array}{l}\text { Breed of animal: } \\
\text { Zebu }=1 \text { if indigenous (Maasai Zebu) } \\
\text { breed ; } 0 \text { otherwise }\end{array}$ \\
\hline Good-exc & $\begin{array}{l}\text { Body condition score of animal: } \\
\text { Good-exc }=1 \text { if in 'good or excellent' } \\
\text { body condition; } 0 \text { otherwise }\end{array}$ \\
\hline Weight & Estimated dressed weight of animal \\
\hline \multicolumn{2}{|l|}{ Buyer- specific attributes } \\
\hline $\begin{array}{l}\text { Typology of buyer/purpose of buying } \\
\text { animal }\end{array}$ & $\begin{array}{l}\text { Declared purpose /motivation for animal } \\
\text { purchase: } \\
\text { Slaughter = } 1 \text { if buying for slaughter; } 0 \\
\text { otherwise } \\
\text { Resale = } 1 \text { if buying to resell to others, } 0 \\
\text { otherwise } \\
\text { Breeding = } 1 \text { if buying for 'home' } \\
\text { breeding/rearing, } 0 \text { otherwise }\end{array}$ \\
\hline
\end{tabular}

\subsection{Buyer types and number of latent segments}

As mentioned earlier, formal statistical tests for the number of segments in the population are not available. We use three information criteria often employed in logit models with finite mixing as a guide to how many segments to retain (increasing the number of segments until the criterion is minimized). These were: the Akaike Information Criterion (AIC), its variant AIC3 and the classic Bayesian Information Criterion (BIC) (Wedel and Kamakura, 2000). A series of models with increasing values of $S$ from 2 to 12 were estimated to compute the respective statistics. This was done for models in which buying purpose (slaughter and resale) was included as determinant of segment membership and for models in which no determinant (except for a segment-specific constant) was fitted in the logit membership probability model.

Across models with the same number of segments the joint restrictions implied by the null of "no determination of segments by buying purpose" can be tested with conventional model specification tests. We used the likelihood ratio test, which rejects the null at all number of segments. We conclude that the data are corroborating our maintained hypothesis. That is, buying purpose is a significant determinant of segment membership. Figure 2 describes the pattern observed in the information criteria used for the determination of the number of segments. The values of the criteria show no clear-cut convergence on a given number of segments. The BIC suggests that the addition of an $8^{\text {th }}$ segment would not improve fit, while AIC suggests that one should stop at a 10-segments model and the AIC3 predicts adding up to 12 segments to the model. Furthermore, all of these models show large numbers of insignificant parameters across segments. 


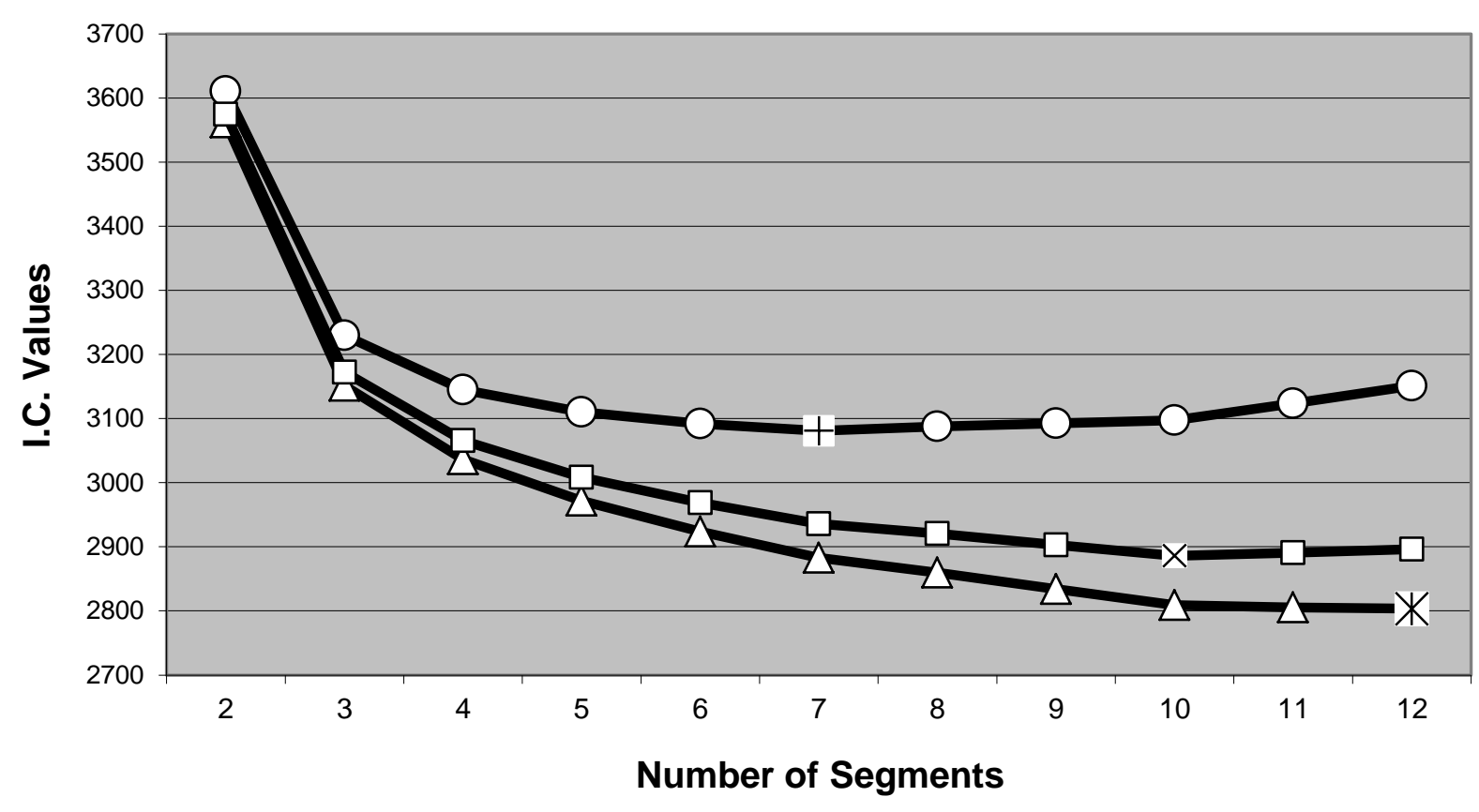

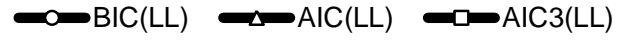

Figure 2. Information criteria values of various latent class models

As mentioned earlier, rather than being mechanically driven by the information in the data, and in the absence of statistically sound indicators, the selection of the number of segments must also take into account the significance of parameter estimates and be tempered by the analyst's own judgment on the interpretability of the model (Swait, 1994), as well as the maintained theoretical prior information. As a result, given the obvious importance of the three dominant types of buyers in these markets, we resort to present and discuss in detail the empirical results derived for the model with three segments.

\subsection{Parameter estimates of the optimal model}

Table 3 presents maximum likelihood parameter estimates for the three segment model $^{5}$. The top block of the table, hereinafter referred to as the 'choice model', shows the estimated parameters $\left(\beta_{\mathrm{s}}\right)$ of the segment-specific utility functions while the bottom block, hereinafter referred to as the segment membership model, shows the corresponding parameters $\left(\lambda_{\mathrm{s}}\right)$ for the segment membership functions. Examination of Table 3 demonstrates that there is substantial heterogeneity in preferences for cattle attributes across segments as indicated by differences in the magnitude, significance and signs of the choice model parameter estimates.

\footnotetext{
${ }^{5}$ For a non linear model of this type, the level of explanatory power is noteworthy with pseudo- $R^{2}$ value of 0.48 . In fact, Louviere et al. (2000) (p. 54) equivalence pseudo- $R^{2}$ values of between 0.2 and 0.4 to $R^{2}$ values of 0.7 to 0.9 obtained in OLS regression applications.
} 
Table 3: Parameter estimates of the optimal latent class model

\begin{tabular}{|c|c|c|c|c|c|c|}
\hline \multirow{2}{*}{ Choice mode } & \multicolumn{2}{|l|}{ Segment 1} & \multicolumn{2}{|l|}{ Segment 2} & \multicolumn{2}{|l|}{ Segment 3} \\
\hline & & & & & & \\
\hline Attribute $X$ & Parameter & $\mid z$-value $\mid$ & Parameter & $\begin{array}{l}\mid z- \\
\text { value }\end{array}$ & Parameter & $\mid z$-value $\mid$ \\
\hline Price & -0.0005 & 8.0 & -0.0007 & 6.2 & -0.0003 & 4.7 \\
\hline Cow & -0.295 & 2.0 & -0.152 & 0.3 & 1.407 & 4.6 \\
\hline Good_exc & 2.088 & 5.0 & 10.96 & 8.5 & -1.409 & 4.8 \\
\hline Weight $(\mathrm{Kg})$ & 0.057 & 12.7 & 0.020 & 2.8 & 0.036 & 8.2 \\
\hline Zebu & -0.208 & 1.8 & -0.479 & 1.4 & -0.145 & 0.8 \\
\hline \multicolumn{7}{|c|}{ Segment membership model } \\
\hline Attribute $\mathrm{Z}$ & & & & & 2.572 & 12.2 \\
\hline \multicolumn{7}{|l|}{ (Breeding) } \\
\hline & 0.870 & 2.7 & -3.443 & 15.6 & & \\
\hline Slaughter & 0.091 & 0.2 & 4.552 & 12.2 & -4.643 & 9.1 \\
\hline Resale & 0.620 & 1.8 & 2.212 & 5.0 & -2.832 & 8.4 \\
\hline
\end{tabular}

Log-likelihood = $-1,555 ;$ Pseudo- $R^{2}=0.484$; Adjusted Pseudo- $R^{2}=0.477$

The parameter estimates in the segment membership model represent the effects of being a buyer with a given motivation on the probability of membership in the various segments. Unlike models with higher number of segments these effects are quite significant with meaningful signs. In particular, all the three dummy variables for buyer type are significant in the membership probability to segments 2 and 3 . The individual signs and magnitudes indicate that resale and breeding buyers are less likely to be in segment 2 than in the base segment, while buyers for slaughter are more likely to be represented in segment 1 and 2 . Breeders and resalers seem to have a significant probability of having some shares in segment 1 , while those buying for slaughter do not have a significant effect of belonging to segment 1. As a consequence, the results indicate that buyers for slaughters are unlikely to display the pattern of preferences described in segment 3 , while resalers and breeders are unlikely to display taste preferences represented in segment 2.

To further characterize the structure of preferences in each segment we used the estimated parameters to compute the membership probability of each 'type' of buyer to each segment. This helps us to establish how the three segments draw their membership from the three main buyer groups (slaughter, resale and breeding). Table 4 presents segment membership probabilities conditional on the three main buyer profiles as implied by the parameters of the segment membership model. 
Table 4: Segment membership probabilities conditional on buyer type and shares

\begin{tabular}{llll}
\hline Attribute Z & Segment1 & Segment2 & Segment3 \\
\hline Breeding & 0.154 & 0.002 & 0.844 \\
Slaughter & 0.431 & 0.547 & 0.023 \\
Resale & 0.807 & 0.053 & 0.140 \\
Segment size (\%) & 0.538 & 0.241 & 0.220 \\
\hline
\end{tabular}

The results in Table 4 show the following. Breeders have the highest membership probability to segment $3(0.844)$, and only a secondary probability $(0.154)$ of being in segment 1. Those buying for slaughter are most likely to be in segment 2 (membership probability $=0.547$ ) but also have a sizeable membership probability in segment 1 (0.431). Finally, those interested in buying heads of cattle for resale tend to belong to segment 1 (membership probability $=0.81$ ) with a smaller probability of membership in segment 3 of 0.14 . Combining these conditional probabilities with the frequencies of breeders (18\%), slaughter buyers (40\%) and resalers (42\%) in the sample, it becomes apparent that resalers have the highest share $(62.8 \%)$ of segment 1 , followed by those buying for slaughter (32\%). We therefore label segment 1 'resalers/slaughter'. Slaughter purchasers have by far the largest share of segment 2 (over 90\%), so we label this segment only as 'slaughter'. Finally, breeders dominate segment 3 with $69.2 \%$, followed by resalers $(26.7 \%)$ hence this segment is named 'breeders/resalers'. Segment 1 is largest with about 54 percent of the sample, followed by segment 2 with 24 percent and segment 3 with 22 percent.

\subsection{Characterization of preferences across segments}

The assignment of buyers to segments and the derivation of segment sizes facilitate a more intuitive characterization of the structure of preferences in each segment. A close comparison of the choice model parameter estimates in Table 3 with the segment membership results in Table 4 is instructive, both in terms of explaining choice behavior and in informing policy. Of particular interest are segment specific MRS values implied by the choice model parameters reported in Table 5 using equation 6. The relative magnitudes of the MRS estimates show the presence of substantial heterogeneity in preferences across the segments.

Table 5: Segment specific marginal values of cattle attributes (Ksh)

\begin{tabular}{llll}
\hline & $\begin{array}{l}\text { Segment 1 } \\
\text { (Resalers/slaughter) }\end{array}$ & $\begin{array}{l}\text { Segment 2 } \\
\text { (Slaughter) }\end{array}$ & $\begin{array}{l}\text { Segment 3 } \\
\text { (Breeders/resalers) }\end{array}$ \\
\hline Cow & -590 & -217 & 4,691 \\
& $\left(270^{\mathrm{a}}\right)$ & $(617)$ & $(1,402)$ \\
Good-exc & 4,175 & 15,663 & $-4,697$ \\
& $(1211)$ & $(4,096)$ & $(1,154)$ \\
Weight & 113 & 29 & 120 \\
& $(21)$ & $(12)$ & $(33)$ \\
Zebu & -416 & -684 & -484 \\
& $(223)$ & $(460)$ & $(576)$ \\
\hline
\end{tabular}

${ }^{\mathrm{a}}$ asymptotic standard errors approximated by means of the delta method 
The results show that different buyer groups trade off cattle attributes differently and this may have relevant repercussions on policy design. Breeders (predominantly in segment 3) are shown to prefer female animals plausibly as breeding stock and for herd re-stocking purposes. Interestingly, they discount animals in good/excellent body condition. A likely explanation is that many breeders prefer to buy animals in poor body condition at a bargain price (e.g. in the dry season) with the intention of fattening them at home (e.g. in the wet season or if they are endowed with more land and pasture).

The slaughter buyers (segment 2) seems to be indifferent in their preferences regarding the sex of animal (judging by the lack of statistical significance of the 'Cow' attribute), but are willing to pay a relatively low premium of about Ksh 30 per kilo so as to maximize their profits. As was expected, this group attaches quite a high premium for animals in good or excellent body condition ${ }^{6}$ probably because of the higher meat quality they carry, but they are indifferent to the indigenous Zebu breeds. The slaughter/resale buyer group (segment 1) prefers male animals, is relatively attracted to animals in good body condition and value the weight of animal in line with the prevailing market price (around Ksh. 100/kilo at the time of the survey). However, they value Maasai zebu cattle by a value of approximately Ksh. 400 less than exotic breeds.

It is also noteworthy that slaughter buyers exhibit a higher sensitivity to price compared to their counterparts. For example, this differential sensitivity to price in turn translates to breeders and resalers being willing to pay a much higher premium per kilo compared to the slaughter group. This result seems reasonable given that slaughter traders may be expected to be primarily motivated by 'quick' profits and to hold on to their money more tightly. In contrast, breeders and resalers may not be primarily motivated by profit (at least in the short term) as they are likely to be more interested in the longer term potential of the animal and hence more willing to pay a higher price to obtain animals with preferred characteristics.

The key result is that the three types of buyer seem to favor exotic rather than indigenous breeds. The results also demonstrate the methodological and substantive merits of the latent segmentation approach. For example, out-of-sample buyers can be allocated to segments with differential preference structures on the basis of information on the purpose for animal purchase alone. Such stratification can be used to tailor breeding or conservation policies to different buyer groups and/or assess the distribution of the effects of such policy actions among market players. Given that information on individual motivations for buying cattle can be collected easily and relatively cheaply in Kenyan livestock markets, the model's potential practical application is appealing. For example, results from such a model can be used to target incentives for breed conservation and/or to implement policy actions tailored to each particular segment. It should be noted however that no segment is characterized solely by one motive underlying purchase decisions.

\footnotetext{
${ }^{6}$ In view of the relatively large MRS values for the body condition attribute, it may well be that this attribute was overvalued in some cases. To illustrate body conditions to respondents some enumerators systematically used laminated photographs, while others chose to point to an animal within view as an example of a particular body condition. It may well be that those that used photos were showing respondents examples of cattle whose body condition was much better than those of even the best cattle in the market. As a result the body condition effect may well have been systematically overvalued.
} 


\section{Conclusions}

This paper reports results from a choice experiment study aimed at characterizing heterogeneity of buyers' preferences over cattle traits in Kenyan livestock markets and assessing the economic value of a typical indigenous breed (Maasai Zebu). A discrete characterization of preference heterogeneity was employed through the use of the latent class model.

The results outlined above show that buyers' preferences are latently clustered around the various motives underlying cattle purchase. They suggest the existence of at least three segments in the population with statistically well defined preferences and the probability of membership in each segment is shown to be significantly related to the various motives underlying cattle purchase (i.e. slaughter, resale and breeding). The segments associated with those buying cattle for the purpose of slaughter or resale account for nearly 80 percent of the sample.

The results show that all the three segments of buyers favor exotic, rather than indigenous breeds. These suggest that there is a comparative lack of economic competitiveness in the indigenous breeds across the buyer population. As pastoral production systems continue to change and as traders specializing in buying animals for slaughter gradually dominate Kenyan cattle markets, there is a very real risk of indigenous breeds being gradually 'pushed' out of the market in favor of exotic breeds. This reflects producers responding rationally to market signals by adopting marketdriven breeding objectives which in many cases mean replacing indigenous breeds with the more 'marketable' exotic breeds.

In general, it emerges that indigenous breeds fail to attract a premium from buyers either ignorant of, or indifferent to, their desirable traits. If it is argued that, in times of uncertainty about future climatic conditions, society should value the attributes of tolerance to drought, disease resistance and poor feeding conditions that are found in indigenous breeds, then such an observation is an example of market failure caused by a lack of appropriate signals or incentives within the market (Bator, 1958) to reflect the potential social benefits of these attributes. Such lack of incentive should therefore be an important consideration to policy makers concerned with the preservation of indigenous cattle in Kenya.

\section{Acknowledgements}

We gratefully acknowledge the financial support of International Livestock Research Institute (ILRI) in the research on which this paper is based. A special thanks to Ed Rege, Patti Kristjanson and Maren Radeny of ILRI for their help. Our appreciation also goes to the Ministry of Agriculture staff in Kajiado district for their assistance in data collection. We, also, would like to thank the anonymous reviewers for their helpful comments. The usual disclaimer applies. 


\section{References}

Anderson, S., 2003. Animal Genetic Resources and sustainable livelihoods. Ecological Economics 45, 331-339.

Ayalew, A., King, J.M, Bruns, E, Rischkowsky, B., 2003. Economic evaluation of smallholder subsistence livestock production: lessons from an Ethiopian goat development programme. Ecological Economics 45, 473-485.

Bator, F. M., 1958. The Anatomy of Market Failure. Quarterly Journal of Economics 72, 351-379.

Batsell, R. R., Louviere, J. J., 1991. Experimental Analysis of Choice, Marketing Letters 2(3), 199-241.

Bekure, S., De Leeuw, P. N. Grandin B. E., Neate P. J. H. (Eds.), 1991. Maasai herding: An analysis of the livestock production system of Maasai pastoralists in eastern Kajiado District, Kenya. ILCA Systems study 4, ILCA (International Livestock Centre for Africa), Addis Ababa, Ethiopia.

Birol, E., Smale, M., Gyovai, A., 2005. Using a Choice Experiment to Estimate Farmers Valuation of Agrobiodiversity on Hungarian Small Farms. Environmental \& Resource Economics 34, 439-469.

Boxall, P. C., Adamowicz, W. L., 2002. Understanding Heterogeneous Preferences in Random Utility Models: A latent Class Approach. Environmental and Resource Economics 23, 421-446.

CBD, 1992. Convention on Biological diversity. CBD Secretariat Online. Accessed January 2007, available at http:/www.biodiv.org/convention/default/shtml

Drucker, A. G., Gomez, V., Anderson, S., 2001. The economic valuation of animal genetic resources: a review of available methods. Ecological Economics 36, 1-18.

Greene, W. H., Hensher, D. A., 2003. A latent class model for discrete choice analysis: contrasts with mixed logit. Transportation Research Part B-Methodological 37(8), 681-698.

Gupta, S., Chintagunta, P. K., 1994. On Using Demographic Variables to Determine Segment Membership in Logit Mixture Models. Journal of Marketing Research 31(1), 128-136.

Hanemann, W. M., 1984. Welfare evaluations in contingent valuation experiments with discrete responses. American Journal of Agricultural Economics 66, 332-341.

Hanotte, O., Bradley, D. G., Ochieng, J. W., Verjee, Y., Hill, E. W., Rege, J. E. O., 2002. African Pastoralism: Genetic Imprints of Origins and Migrations. Science 296, 336-339. 
Hu, W., Hunnemeyer, A., Veeman, M., Adamowicz, W., Srivastava, L., 2004. Trading off health, environmental and genetic modification attributes in food. European Review of Agricultural Economics 31, 389-408

Jabbar, M. A., Diedhiou, M. L., 2003. Does breed matter to cattle farmers and buyers? Evidence from West Africa. Ecological Economics 45, 461-472.

Kamakura, W., Russel, G. J., 1989. A Probabilistic Choice Model for Market Segmentation and Elasticity Structure. Journal of Marketing Research 26(4), 379-390.

Louviere, J. J., Hensher, D. A., Swait, J. D., 2000. Stated Choice Methods: Analysis and Applications. Cambridge University Press, Cambridge.

Maren, R., Kristjanson, P., Ruto, E., Scarpa, R., Wakhungu, J., 2006. Determinants of cattle prices in Southern Kenya: Implications for breed conservation and pastoral marketing strategies. In: McPeak, J. G., Little, P. D. (Eds.), Pastoral Livestock Marketing in Eastern Africa: Research and Policy Changes. ITDG Publishing, Rugby.

McFadden, D., 1974. Conditional logit analysis of qualitative choice behavior. In: Zarembka, P. E. (Ed.), Frontiers of Econometrics. Academic Press, New York.

McFadden, D., Train, K., 2000. Mixed MNL models of discrete response. Journal of Applied Econometrics 15(5), 447-470.

McLachlan, G., Peel, D., 2000. Finite Mixture Models. John Wiley and Sons, New York.

Morey, E., Thatcher, J., Breffle, W., 2006. Using Angler Characteristics and Attitudinal Data to Identify Environmental Preference Classes: A Latent-Class Model. Environmental \& Resource Economics 34, 91-115.

Mwacharo, J., Mosi, R., 2002. A review of current and previous attempts at genetic improvement of Small East African Shorthorn Zebu (SEAZ) cattle in Kenya. Paper presented at the consultative workshop on Cattle and Goat Breeding in East Africa, 15-17 April 2002, United Kenya Club, Nairobi.

Provencher, B., Baerenklau, K., Bishop, R., 2002. A finite mixture logit model of recreational angling with serially correlated random utility. American Journal of Agricultural Economics 84(4), 1066-1075.

Rege, J. E. O., 1999. The state of African cattle genetic resources I. Classification framework and identification of threatened and extinct breeds. Animal Genetic Resources Information 25, 1-25.

Rege, J. E. O., Gibson, J. P., 2003. Animal genetic resources and economic development: issues in relation to economic valuation. Ecological Economics 45, 319330 . 
Rege, J. E. O., Kahi, A., Okomo-Adhiambo, M., Mwacharo, J., Hanotte, O., 2001. Zebu cattle of Kenya: Uses, performance, farmer preferences and measures of genetic diversity. ILRI (International Livestock Research Institute), Nairobi, Kenya.

Roosen, J., Fadlaoui, A., Bertaglia, M., 2005. Economic evaluation for conservation of farm animal genetic resources. Journal of Animal Breeding and Genetics 122, 217 228.

Ruto, E., 1999. Livestock marketing in Kenya's rangelands: The case of Kajiado district, Kenya. Unpublished market research document, Kenya Agricultural Research Institute, Kiboko, Kenya.

Ruto, E., 2004. Economic valuation of farm animal genetic resources: Methods and Applications to Indigenous Cattle in Kenya. Ph.D. Thesis. Newcastle University, UK.

Scarpa, R., Ruto, E. S. K., Kristjanson, P., Radeny, M., Drucker, A., Rege, J. E. O., 2003a. Valuing indigenous cattle breeds in Kenya: an empirical comparison of stated and revealed preference value estimates. Ecological Economics 45, 409-426.

Scarpa, R., Drucker, A., Anderson, S., Ferraes-Ehuan, N., Gomez, V., Risopatron, C. R., Rubio-Leonel, O., 2003b. Valuing genetic resources in peasant economies: the case of 'hairless' creole pigs in Yucatan. Ecological Economics 45, 427-443.

Scarpa, R., Thiene, M., 2005. Destination Choice Models for Rock Climbing in the Northern Alps: A latent-Class Approach Based on Intensity of Preference. Land Economics 81(3), 426-444.

SPSS, 2000. SPSS for Windows, Release 10.0.7. Spss Inc. Chicago.

Swait, J., 1994. A structural equation model of latent segmentation and product choice for cross-sectional revealed preference choice data. Journal of Retailing and Consumer Services 1(2), 77-89.

Tano, K., Kamuanga, M., Faminow, M. D., Swallow, B., 2003. Using conjoint analysis to estimate farmer's preferences for cattle traits in West Africa. Ecological Economics 45, 393-407.

Train, K., 2003. Discrete choice methods with simulation. Cambridge University Press, Cambridge.

Wedel, M., Kamakura, W., 2000. Market Segmentation: Conceptual and Methodological Foundations. Kluwer Academic Publishers, Boston, MA. 